Article title: Benefits and Challenges of ODeL in Postgraduate Education: The Case of Unisa-Ethiopia Authors: Tsige GebreMeskel Aberra[1]

Affiliations: University of South Africa[1]

Orcid ids: 0000-0003-4798-0096[1]

Contact e-mail: abertg@unisa.ac.za

License information: This work has been published open access under Creative Commons Attribution License $\mathrm{http}: / / c r e a t i v e c o m m o n s . o r g / l i c e n s e s / b y / 4.0 /$, which permits unrestricted use, distribution, and reproduction in any medium, provided the original work is properly cited. Conditions, terms of use and publishing policy can be found at https://www.scienceopen.com/.

Preprint statement: This article is a preprint and has not been peer-reviewed, under consideration and submitted to UnisaRxiv for open peer review.

DOI: 10.25159/UnisaRxiv/000018.v1

Preprint first posted online: 01 July 2021

Keywords: open distance e- learning, benefits, challenges, doctoral graduates, Ethiopia 


\title{
Benefits and Challenges of ODeL in Postgraduate Education: The Case of Unisa-Ethiopia
}

\author{
Tsige GebreMeskel Aberra \\ https://orcid.org/0000-0003-4798-0096 \\ Ethiopia Regional Learning Centre, University of South Africa \\ abertg@unisa.ac.za
}

\begin{abstract}
The focus of this paper is on identifying the benefits and the challenges of the open distance e-learning mode of education and their relationship with learners' satisfaction. A total of 78 master's and doctoral graduates responded to a 35item 7-dimensional Likert-scale questionnaire that consisted of 2 open-ended items that allowed respondents to write their reflections. Means, standard deviations, Pearson's correlation and stepwise regression were used to analyse the quantitative data, whereas the data from the open-ended items were analysed thematically. The results showed that studying in the open distance e-learning system assists learners to develop professional competence, personality skills and computer skills. It has given them access to postgraduate education, accomplishment of problem-solving research, studying from the comfort of home while earning a living, access to rich library resources, and increased life skills such as research language and independent learning. Although the benefits outweighed the challenges, the main challenge that stood out in this paper was the lack of supervision support. Other challenges were loss of motivation, procrastination, poor internet connections, lack of human touch, and lack of support from employers. The paper recommends that open distance e-learning institutions improve their supervision systems and ensure that their student support systems contribute to curbing students' challenges including feelings of isolation.
\end{abstract}

Keywords: open distance e-learning, benefits, challenges, doctoral graduates, Ethiopia

\section{Background}

Distance education developed from print and correspondence to the current fully online digital format. The nature of distance education presupposes the employment of the contemporary technology with the main reason of bridging the gap in the geographic separation and differences in time zones between learners and teachers (Sarrab, AlShihi, and Hussien Rehman 2013, 831). Since the mid-1990s, information and communications technology (ICT) has made a significant change in the distance education platform. The media have changed from written to web-based (online) technologies that have changed open distance learning (ODL) to open distance electronic learning (ODeL) both in the process of teaching and learning and learner 
support services. If a person has the necessary IT devices and internet connectivity, access to knowledge is possible and the person does not need to go to a conventional classroom setting to learn (Arinto 2016, 165; Sadeghi 2019, 85).

ODeL enhances learning and human capital development (Sarrab, Al-Shihi, and Hussien Rehman 2013, 827). In the African context, ODeL has numerous benefits. It expands access to education because learners who reside in remote areas can access education provided that they have the mobile phone and internet connectivity. It is affordable to many learners as compared to conventional education. It allows flexibility of what to learn, when to learn and at which pace (Kamper and Du Plessis 2014, 81; Karsenti and Collin 2012, 9).

ODeL also considers learners' health issues when some students may need to regularly visit health institutions and cannot sit in conventional schools. Moreover, learners can access a multitude of information on the web, social interaction among them is enhanced, and they get knowledge and certification from higher education (HE), which in turn expands their employability (self-employment or otherwise). Some learners also use ODeL for personal satisfaction and making constructive use of their time by getting engaged in education (Butcher and Rose-Adams 2015, 133-134).

Similarly, ODeL is a student-centred system whereby students are self-directed to decide what and when to learn and to get individualised support. Students are made to learn independently with minimal guidance from education providers (Arkroful and Abaidoo 2014, 401; Kamper and Du Plessis 2014, 81). It is affirmed that ODeL "helps learners take control of their education and provides them with opportunities to learn at their own pace at times and places compatible with their life commitments" (Dirani and Yoon 2009, 2; Gilbert 2015, 6).

The benefits of ODeL also include focusing on the individualised needs of the students rather than on the needs of the teachers (facilitators) and the institution. Students benefit from gaining knowledge and qualification without being affected by different factors such as cultural diversity or physical ability. ODeL is flexible and is therefore not affected by time and geographic location. It is not affected by age, gender, ethnic origin, physical ability or the nature of work (part-time or full-time) (Arkroful and Abaidoo 2014, 401-402; Butcher and Rose-Adams 2015, 133).

The benefits of ODeL as stated by Kisanga and Ireson $(2015,126)$, are contextualised in this paper in the following manner: "access to quality educational materials" is facilitated at the University of South Africa (Unisa) through its library which houses multitudes of peer-reviewed journals and which are accessed online by the postgraduate students. It is said that, being a Unisa student, the challenge is which one to choose to read and not a shortage of what to read. Another benefit, "electronic communication," is Unisa's dedicated email system called "myLife" which is used by students to communicate with their supervisors, lecturers and the whole Unisa community. This is 
in addition to the "myUnisa" learning management system through which students send assignments, receive feedback, receive exam schedules, and check grades. Another benefit "learning flexibility" can be translated to mean that the content of students" research is by and large their own decision. These authors identified "pace of learning" as another benefit. In the context of this paper, students are the drivers of their learning if they push their research work faster, they can finish their studies earlier than students who study at a slow pace.

Owing to being an ODeL institution and being cognisant of the numerous benefits of ODeL, Unisa was tasked to assist the Government of Ethiopia in its effort to develop human capital. This was as a result of the Relationship of Cooperation that was signed in 2004 between the governments of Ethiopia and South Africa (in the form of SouthSouth cooperation). To materialise this initiative, education was regarded as one of the aspects of cooperation. This led to the establishment of the Unisa-Ethiopia Regional Learning Centre, which was proceeded by the Bilateral Agreement that was signed between the governments of Ethiopia and South Africa in 2006. The Centre started operating in 2007 and focuses on enrolling postgraduate students in different disciplines. Since 2009, the number of enrolments for doctoral studies has increased and Unisa has graduated a significant number of students who mostly serve public universities in Ethiopia. This initiative therefore gave access to many Ethiopians to study for postgraduate degrees. They also undertook their studies while working and also without separating from their families.

The challenges of ODeL include ODeL learners being challenged by poor ICT infrastructure, the lack of access to computer laboratories, and unstable power supply. The learners have responsibilities at work and home which consume their study time. The learners do not get support from their lecturers and feedback from their lecturers either arrives late or might not be adequate. Employers do not always give the learners the necessary support. ODeL is often regarded as inferior to conventional education. Such challenges negatively affect the learners' motivation and success, resulting in more dropout rates (Musingafi et al. 2015, 60-62). Another major challenge is the lack of personal or human touch between teachers and students and also among the students, resulting in feelings of isolation (Arkroful and Abaidoo 2014, 402; Tareen and Haand 2020, 87).

Musingafi et al. $(2015,60)$ cited Cross who categorised the challenges of learners into three factors, namely, situational, institutional, and dispositional. Situational challenges can be described as the learners' responsibilities at work and in the house that take away their time to concentrate on their study. The inability to operate ICTs, poor infrastructure, and student support services such as tutorials and library services can be regarded as institutional factors. Thirdly, personality factors can be described as students' perceptions of the ODeL mode of education (its provisions and demands), time management skills, and procrastination. 
When the challenges of ODeL are translated into the complaints of Ethiopian students enrolled at Unisa, the following challenges emerge: delayed assignments by the supervisors and slow or no responses from the supervisors regarding the submissions (proposals or chapters) by the students which were recorded in fact-finding sessions with officials of Unisa long before this paper was conceptualised. The students also reported the slow delivery of books requested from the main campus library and search librarians taking too long to share the requested materials. Moreover, the students found the myLife and myUnisa accounts not user-friendly and requiring a strong internet connection.

With this background, this paper tries to explore the benefits and challenges of ODeL among the postgraduate group of students with the purpose of presenting recommendations. This paper can also be of value in the field of ODeL research as its respondents were solely postgraduate students most of whom were doctoral students, which is relatively scarce.

\section{Research Questions}

Based on the research background as previously stated, this paper tries to answer the following questions:

- What benefits have the graduates gained as a result of studying at Unisa, which is an ODeL university?

- What challenges did the graduates face in the course of studying in the ODeL system?

- What lessons can be learned from identifying the benefits and challenges of the graduates?

\section{Research Objectives}

This paper focuses on dealing with the following three objectives:

- exploring the benefits of ODeL graduates;

- outlining the challenges the graduates faced; and

- presenting recommendations as a result of the findings.

\section{Methodology}

\section{Study Population}

The study population consisted of graduates of the Unisa-Ethiopia Centre in the period of 2015 to 2018. They were students of course work or research master's and doctoral studies. A total of 210 graduates were found in the list. From these, 78 participated in the study. The profiles of the respondents showed that 95 per cent were male students, 
90 per cent graduated with doctoral degrees, and 60 per cent were sponsored by the government.

\section{Data Collection Procedure}

A questionnaire was designed to collect data from the graduates. The questionnaire had 34 Likert-scale items that focus on identifying the graduates' benefits and challenges while passing through the ODeL system. The items were categorised into seven dimensions, namely, general advantages of ODeL, personal challenges, computer skills, professional competence, personality skills, environmental challenges, and opportunities. Another item was added to measure the students' overall satisfaction. To complement the quantitative data, two open-ended items were added so that the graduates write points pertaining to the benefits and challenges of ODeL as experienced during their stay as postgraduate students of Unisa. This was done with the purpose of enriching the findings from the quantitative data and also to obtain ideas that could not have been covered by the items in the quantitative part.

\section{Data Analysis Techniques}

Descriptive statistics (means and standard deviations) were used to show the level of the benefits and the challenges of ODeL as reported by the graduates. Pearson's correlation and stepwise regression were employed to observe the relationship between (1) the overall benefits and satisfaction, (2) the overall challenges and satisfaction, and (3) which dimensions mostly contributed to explaining the graduates' satisfaction. The data that were collected by the open-ended items were analysed thematically.

\section{Findings}

\section{Quantitative Data Analysis}

The section below presents the findings of this paper as collected from 78 postgraduate education graduates of the Unisa-Ethiopia Centre. Five dimensions, namely, the general advantages, computer skills, professional competence, personality skills, and opportunities were used to gain an understanding of the benefits of ODeL according to the experiences of the graduates. Table 1 presents the findings.

Table 1: Benefits of ODeL

\begin{tabular}{|c|c|c|c|c|c|c|}
\hline Dimension & Items & $\mathbf{N}$ & Min. & Max. & Mean & SD \\
\hline \multirow{5}{*}{$\begin{array}{l}\text { General } \\
\text { advantages }\end{array}$} & Flexibility in using own time & 78 & 1 & 5 & 4.40 & .709 \\
\hline & Fulfilling dreams of studying in HE & 77 & 2 & 5 & 4.26 & .880 \\
\hline & $\begin{array}{l}\text { Studying in the comfort of home and } \\
\text { family }\end{array}$ & 78 & 2 & 5 & 4.42 & .876 \\
\hline & Studying while working & 78 & 2 & 5 & 4.54 & .638 \\
\hline & Affordable & 72 & 1 & 5 & 3.26 & .888 \\
\hline \multicolumn{5}{|c|}{ Grand mean and standard deviation } & 4.19 & 0.48 \\
\hline \multirow{2}{*}{$\begin{array}{l}\text { Computer } \\
\text { skills }\end{array}$} & Increased computer skills & 78 & 1 & 5 & 3.99 & .960 \\
\hline & Enabled to access updated & 78 & 2 & 5 & 4.42 & .635 \\
\hline
\end{tabular}




\begin{tabular}{|c|c|c|c|c|c|c|}
\hline Dimension & Items & $\mathbf{N}$ & Min. & Max. & Mean & SD \\
\hline & information & & & & & \\
\hline & $\begin{array}{l}\text { Gained skills of extended internet } \\
\text { browsing }\end{array}$ & 78 & 2 & 5 & 4.36 & .772 \\
\hline \multicolumn{5}{|c|}{ Grand mean and standard deviation } & 4.26 & 0.65 \\
\hline \multirow{5}{*}{$\begin{array}{l}\text { Professional } \\
\text { competence }\end{array}$} & Enhanced professional competency & 78 & 2 & 5 & 4.54 & .638 \\
\hline & Expanded research skills & 78 & 2 & 5 & 4.69 & .565 \\
\hline & Became critical thinkers & 78 & 2 & 5 & 4.55 & .617 \\
\hline & $\begin{array}{l}\text { Encouraged to take assignments that } \\
\text { need careful analysis }\end{array}$ & 76 & 1 & 5 & 4.33 & .855 \\
\hline & Encouraged to publish in journals & 75 & 1 & 5 & 3.92 & .969 \\
\hline \multicolumn{5}{|c|}{ Grand mean and standard deviation } & 4.41 & 0.54 \\
\hline \multirow[t]{5}{*}{$\begin{array}{l}\text { Personality } \\
\text { skills }\end{array}$} & $\begin{array}{l}\text { Increased motivation to face } \\
\text { challenges }\end{array}$ & 78 & 2 & 5 & 4.38 & .629 \\
\hline & $\begin{array}{l}\text { Became independent in executing } \\
\text { duties }\end{array}$ & 78 & 3 & 5 & 4.71 & .512 \\
\hline & Developed strong work ethics & 78 & 3 & 5 & 4.58 & .635 \\
\hline & $\begin{array}{l}\text { Developed better time-management } \\
\text { skills }\end{array}$ & 77 & 2 & 5 & 4.31 & .712 \\
\hline & $\begin{array}{l}\text { Became committed to assist junior } \\
\text { researchers }\end{array}$ & 77 & 2 & 5 & 3.97 & .743 \\
\hline \multicolumn{5}{|c|}{ Grand mean and standard deviation } & 4.39 & 0.47 \\
\hline \multirow[t]{3}{*}{ Opportunities } & Extended job opportunities & 78 & 1 & 5 & 3.67 & 1.089 \\
\hline & Added responsibilities & 78 & 1 & 5 & 4.03 & .980 \\
\hline & Financial benefit & 78 & 1 & 5 & 3.49 & 1.159 \\
\hline \multicolumn{5}{|c|}{ Grand mean and standard deviation } & 3.73 & 0.93 \\
\hline
\end{tabular}

As shown in Table 1, the means of the graduates' responses are above 4.0 out of the scale of 5.0 for most of the items in the questionnaire. Regarding the standard deviations, the responses of the graduates do not show high variation as they are all below 1.0. The highest grand mean goes to the dimension of professional competence (mean $=4.41)$, which is closely followed by personality skills $($ mean $=4.39)$ that the graduates have developed through studying under the ODeL system of education at Unisa. The rest of the dimensions hold means that are well above average. These results showed the benefits the graduates obtained from studying under the ODeL mode of education. Similarly, the relationship between the graduates' satisfaction was observed against the benefits by using Pearson's correlation. The result showed that there was a statistically significant moderate and positive relationship between the two factors; $\mathrm{r}=0.4$ at $p$ value of 0.01 .

The challenges the graduates faced while studying in the ODeL system at Unisa are presented in Table 2. In this paper, the challenges of ODeL were explored using two dimensions, namely, personal challenges and environmental challenges. 
Table 2: Challenges of ODeL

\begin{tabular}{|c|c|c|c|c|c|c|}
\hline DIMENSION & ITEMS & $\mathbf{N}$ & Min. & Max. & Mean & SD \\
\hline \multirow[t]{6}{*}{ Personal challenges } & $\begin{array}{l}\text { Feelings of isolation and } \\
\text { loneliness }\end{array}$ & 78 & 1 & 5 & 2.68 & 1.222 \\
\hline & Procrastination & 78 & 1 & 5 & 3.29 & 1.186 \\
\hline & Continued interruption & 78 & 1 & 5 & 3.67 & 1.089 \\
\hline & Temptation to quit & 78 & 1 & 5 & 2.96 & 1.284 \\
\hline & $\begin{array}{l}\text { Problem of adaptability to the } \\
\text { ODeL system }\end{array}$ & 77 & 1 & 5 & 3.35 & 1.121 \\
\hline & $\begin{array}{l}\text { Loss of motivation at some } \\
\text { point during the study }\end{array}$ & 74 & 1 & 5 & 3.51 & 1.162 \\
\hline \multicolumn{5}{|c|}{ Grand mean and standard deviation } & 3.24 & 0.78 \\
\hline \multirow{7}{*}{$\begin{array}{l}\text { Environmental } \\
\text { challenges }\end{array}$} & Frequent power outages & 74 & 2 & 5 & 3.76 & 1.070 \\
\hline & $\begin{array}{l}\text { Lack of stable internet } \\
\text { connections }\end{array}$ & 78 & 2 & 5 & 3.85 & 1.152 \\
\hline & $\begin{array}{l}\text { Degree regarded as inferior } \\
\text { by others }\end{array}$ & 78 & 1 & 5 & 2.06 & 1.085 \\
\hline & Lack of workplace support & 78 & 1 & 5 & 3.10 & 1.295 \\
\hline & $\begin{array}{l}\text { Not having an environment } \\
\text { that is conducive to learning }\end{array}$ & 77 & 1 & 5 & 2.97 & 1.100 \\
\hline & $\begin{array}{l}\text { Distant location of the } \\
\text { Ethiopia Centre }\end{array}$ & 78 & 1 & 5 & 3.82 & 1.181 \\
\hline & $\begin{array}{l}\text { Not getting immediate } \\
\text { feedback }\end{array}$ & 73 & 1 & 5 & 3.47 & 1.395 \\
\hline \multicolumn{5}{|c|}{ Grand mean and standard deviation } & 3.29 & 0.67 \\
\hline
\end{tabular}

These two dimensions of challenges of ODeL are closely similar in their mean values. The variation was also small showing that the graduates have given almost similar responses. The relationship between the graduates' satisfaction and the challenges they experienced were observed by means of Pearson's correlation, and there is a statistically significant, weak and negative relationship between the graduates' satisfaction and the challenges that they faced; $\mathrm{r}=-.27$ at $p<0.05$.

The other finding in this paper was identifying which of the dimensions contributed to satisfaction more than the others. By employing stepwise regression, all seven dimensions were weighed. The results show that only one dimension, namely professional competence, stood out to explain the variation in satisfaction at 14 per cent $(\mathrm{R}=0.38)$ as shown in Table $1 ; \mathrm{R}^{2}=0.14 \mathrm{~F}_{(1,75)}=12.24, p<0.001$.

\section{Qualitative Data Analysis}

In the open-ended item that asked the respondents to state the benefits of studying at Unisa as an ODeL university, the respondents reported that Unisa has given access to many Ethiopian learners who otherwise might not have been able to study for postgraduate degrees. Unisa's varied programmes attract students from different fields of study. One respondent wrote: "It offers opportunities to various professionals to attend for higher learning (accessibility)." 
The respondents also said that the country has benefited by having more qualified personnel in different fields of study (contribution to human capicity development). The issues the students raised in their master's and doctoral research also deal with realistic problems in the country and the recommendations that they make can be used to solve or overcome actual (practical) problems in the different disciplines in the country.

One of the most commonly raised points by the respondents as a benefit of ODeL was the fact that they studied without moving away from home. They said that their family did not face any disruption (stayed stable). One respondent wrote, "smooth and uninterrupted family and education at once." The respondents added that they were studying while working full time, which further led to benefiting their employers because they were serving their employer institutions while gaining knowledge that improves the way they work. One respondent wrote, "studying for higher degree without leaving the comforts of home and family or without displacing workplace." Another one added, "obtaining academic qualification while working."

Studying under ODeL has given the respondents various skills such as improved language and communication skills. For example, one respondent wrote, "I developed writing skills, in particular grammar usage and editing style." In addition, the fact that the examination procedure is demanding made the graduates proficient in producing quality research. ODeL's flexibility taught them skills of managing and planning their own time better. They said that these skills boost their confidence when accomplishing overall duties and research work. The ODeL system has made the graduates skilled in becoming independent (autonomous) when taking up responsibilities. One of the respondents wrote, "it promotes self-learning and drives students to read more and be the prime sources of solutions in life."

The respondents stated that they are satisfied for having graduated from Unisa, which they expressed as a university of reputation and international accreditation. Unisa's valued education is useful in that it has prepared them to compete better in the world. According to one respondent, "Unisa has prestigious identity and getting degree from such institution is a source of pride."

The bursary fund has helped the respondents to finish their studies in good time. The tuition fee is reasonable, and hence it is affordable to many learners who need HE. The academic support was of good quality. Many of the respondents positively commented on the availability and usefulness of the e-library with multitudes of journal subscriptions. One respondent stated that there are "adequate resources in the e-library".

Regarding the challenges reported by the respondents, the most commonly reported challenge was the behaviour of supervisors. Many respondents wrote that there were delayed or no responses from their supervisors. One respondent expressed it bitterly by saying "that's rough/awful/disappointing". Another one wrote, "I think there is no strong system, which makes supervisors accountable for their work." According to the 
respondents, some supervisors took no responsibility for their duties, they were reluctant to assist their students, and delayed feedback for half a year or more. This has caused many students to drop out of the system. One respondent wrote, "dealing with promoters was very difficult while studying at Unisa because some of them were irresponsible and did not respond on time, and even some have no adequate experience in assisting the students." Another respondent wrote, "supervisors and other officials do not either seem to understand the cultural differences, which in turn creates gaps in communication."

Another challenge that was raised by the respondents was the prolonged process of thesis examinations. They wrote that there were times that they had no clue of the whereabouts of their submitted thesis and that they were not getting responses to their emails enquiring about their theses. The respondents wrote that such cases were frustrating experiences.

The lack of support and misunderstanding from their employers were also reported by the respondents. These challenges were more experienced among the respondents who work at local universities and who had been given extra teaching loads and office duties such as department headship. It is also the case that some people and employers underestimate degrees that are obtained through the distance mode of learning. One respondent said: "Some employers discredit degrees obtained through ODeL."

In the course of their studies, the respondents reported to have been challenged by power outages and unstable or weak internet connectivity. This caused a lot of frustration during their studies and they added that they were unable to finish their studies in time.

The lack of face-to-face interaction with supervisors and fellow students was recorded as another challenge. The respondents felt that the drawbacks of the online communication were that emotions and concerns could not be effectively expressed. The respondents reported the lack of working in groups with fellow students.

\section{Discussions and Recommendations}

In this paper, one of the main findings was that ODeL enhances the development of skilled human power, which is described under the dimension of professional competence. This finding is in line with that of the study by Sarrab, Al-Shihi, and Hussien Rehman (2013). Moreover, the benefit of the growth of professional competence aligns with Unisa's mission in Ethiopia; i.e. to develop human capital. Such competence is believed to make the graduates skilled in their profession and enables them to contribute to the development of the country's economy.

The respondents repeatedly stated the benefits of ODeL as expanding access to education, being affordable in terms of fees, and being flexible in managing own time. Such findings were also recorded in the study by Karsenti and Collin (2012). Such benefits of ODeL make the system fit for the ever-growing technological advancement in the global environment. 
The other findings of this paper also showed the graduates' appreciation of the e-library, their qualifications giving them better employment opportunities and the benefit of developing independence in problem-solving that paves the way to becoming selfemployed. Similar to the studies of Kisanga and Ireson (2015) and Arkroful and Abaidoo (2014), the graduates were satisfied for having been able to access quality educational materials in the library, for gaining knowledge and certification from HE that improves their employability and independence.

The environmental challenges of the respondents were related to poor ICT infrastructure and unstable power supply. They also experienced delayed feedback from their supervisors. Their employers did not give them the necessary support nor did they acknowledge the time and commitment that are necessary to study in the ODeL system. These findings were similar to those recorded by Musingafi et al. (2015).

In general, however, both the quantitative and the qualitative findings of this paper reveal that the benefits of studying in the ODeL system outweigh the challenges. The lessons that can be drawn from this paper therefore focus on ODeL's general benefit of helping learners to develop professional competence that enabled them to have professional and research skills in their disciplines. This helps to contribute to enhancing human capital in the country with production of personalities that are critical thinkers, with strong work ethics and time management skills. The mode of education also has the benefit of giving access to education to many people, accomplishing problemsolving research to the country, allowing learners to study while working and without disrupting family life, and developing skills such as academic writing (Tareen and Haand 2020).

In curbing the challenges, ODeL universities should strive to improve their supervision systems. This relates to timely responses with critical feedback that help learners to meaningfully improve their research. The student support systems should also be enhanced to make learners accommodated, to give them a sense of belonging at their university, and to help them avoid feelings of isolation by designing methods in which the students can learn collaboratively (Gilbert 2015).

\section{References}

Arkroful, V., and N. Abaidoo. 2014. "The Role of E-Learning, the Advantages and Disadvantages of its Adoption in Higher Education." International Journal of Education and Research 2 (12): 397-410.

Arinto, P. 2016. "Issues and Challenges in Open and Distance E-Learning: Perspectives from the Philippines." International Review of Research in Open and Distributed Learning 17 (2): 162-80. https://doi.org/10.19173/irrodl.v17i2.1913. 
Butcher, J., and J. Rose-Adams. 2015. "Part-Time Learners in Open and Distance Learning: Revisiting the Critical Importance of Choice, Flexibility, and Employability." Open Learning: The Journal of Open, Distance, and e-Learning 30 (2): 127015037. https://doi.org/10.1080/02680513.2015.1055719.

Dirani, K. M., and S. W. Yoon. 2009. "Exploring Open Distance Learning at a Jordanian University: A Case Study." International Review of Research in Open and Distance Learning 10 (2): 1-18. https://doi.org/10.19173/irrodl.v10i2.599.

Gilbert, B. 2015. “Online Learning Revealing the Benefits and Challenges.” Master's thesis, St. John Fisher College.

Kamper, G. D., and E. C. du Plessis. 2014. "Some Critical Reflections on Open Distance Learning, with Particular Reference to Work-Integrated Learning." Africa Education Review 11 (1): 77-90. https://doi.org/10.1080/18146627.2013.853568.

Karsenti, T., and S. Collin. 2012. "Using IT for Distance Learning: Benefits and Challenges for African Learners.” Informing Science Institute 12; 235-236. https://doi.org/10.28945/1652.

Kisanga, D., and G. Ireson. 2015. "Barriers and Strategies on Adoption of E-Learning in Tanzanian Higher Learning Institutions: Lessons for Adopters." International Journal of Education and Development using Information Communication Technology 11 (2): 12637.

Musingafi, M. C. C., B. Mapuranga, K. Chiwanza, and S. Zebron. 2015. "Challenges for Open and Distance Learning (ODL) Students: Experiences from Students of Zimbabwe Open University." Journal of Education and Practice 6 (18): 59-66.

Sadeghi, M. 2019. "A Shift from Classroom to Distance Learning: Advantages and Limitations." International Journal of Research in English Education 4 (1): 80-88. https://doi.org/10.29252/ijree.4.1.80.

Sarrab, M., H. Al-Shihi, and O. M. Hussien Rehman. 2013. "Exploring the Major Challenges and Benefits of M-Learning Adoption." British Journal of Applied Science and Technology 3 (4): 826-39. https://doi.org/10.9734/BJAST/2013/3766.

Tareen, H., and M. T. Haand. 2020. “A Case Study of UiTM Post-Graduate Students' Perceptions on Online Learning: Benefits and Challenges." International Journal of Advanced Research and Publications 4 (6): 86-94 